\title{
A Genetic Variant in Proline and Serine Rich Coiled-Coil 1 Gene Is Associated with the Risk of Cardiovascular Disease
}

\author{
Mohammad Sadegh Khorrami ${ }^{1,2,3}$, Fatemeh Sadabadi ${ }^{3}$, Alireza Pasdar ${ }^{1}$, \\ Hamide Safarian-Bana ${ }^{3}$, Forouzan Amerizadeh ${ }^{1,2}$, Habibollah Esmaeily ${ }^{3,4}$, \\ Mohsen Moohebati ${ }^{3}$, Alireza Heidari-Bakavoli ${ }^{3}$, Gordon Ferns ${ }^{5}$, \\ Majid Ghayour-Mobarhan*3, Amir Avan*1,2,3
}

\begin{abstract}
Background: Cardiovascular disease is one of the most common causes of morbidity and mortality worldwide. The Proline and Serine Rich Coiled-Coil 1 gene in 1 p13.3 locus has been reported to be associated with low density lipoprotein cholesterol (LDL-C) and coronary artery disease (CAD). The objective of this study was to investigate the association between the rs599839 polymorphism of the Proline and Serine Rich Coiled-Coil 1 (PSRC1) gene with CVD outcomes in a population sample recruited as part of the Mashhad-Stroke and Heart-Atherosclerotic-Disorders (MASHAD) cohort.

Methods: Five hundred and nine individuals who had an average follow-up period of 10 years were enrolled as part of the MASHAD cohort. DNA was extracted and genotyped using the TaqMan-real-time-PCR based method.

Results: The study found individuals with GA/GG genotypes were at a higher risk of CVDs (OR=4.7; $95 \%$ CI, 2.5-8.7; $\mathrm{p}<0.001$ ) in comparison to those with AA genotype; however, the result was not significant for GG genotype data.

Conclusions: The results suggest that the GA/GG genotypes of the PSRC1gene locus were at increased risk of CVD in a representative population-based cohort, demonstrating further functional analysis to discover the value of emerging marker as a risk stratification biomarker to recognize high risk cases.
\end{abstract}

Keywords: Cardiovascular diseases, Cohort studies, Genetic Polymorphism, PSRC1 Gene.

\section{Introduction}

The usual tool for explaining the genetic architecture of polygenic traits is the genomewide association (GWA) study. Commonly, GWA studies assess whether there is a link between individuals were phenotyped for the trait of interest and genotyped at a section of common genetic variants (1). It has provided a unique opportunity to observe, on a large scale, the correlation of common genetic SNP with complex diseases like, cardiovascular disease in the past decade. Furthermore, the GWAS-identified new pathways can predict a new age of novel drug development and classification of patients $(2,3)$.

Cardiovascular diseases (CVDs) are most common non communicable enduring disease,

1: Department of Medical Genetics and Molecular Medicine, Faculty of Medicine, Mashhad University of Medical Sciences, Mashhad, Iran.

2: Student Research Committee, Faculty of Medicine, Mashhad University of Medical Sciences, Mashhad, Iran.

3: Metabolic Syndrome Research center, Mashhad University of Medical Sciences, Mashhad, Iran.

4: Department of Epidemiology and Biostatistics, School of Health, Mashhad University of Medical Sciences, Mashhad, Iran.

5: Brighton \& Sussex Medical School, Division of Medical Education, Falmer, Brighton, Sussex, UK.

*Corresponding author: Ghayour-Mobarhan; Tel: +9851 38002475; E-mail: ghayourm@mums.ac.ir

\& Amir Avan; Tel: +9851 38002298; E-mail: avana@mums.ac.ir.

Received: 28 Jul, 2021; Accepted: 6 Sep, 2021 
which is the chief cause of death globally, accounted for 17.8 million deaths worldwide in 2017 , of which more than $75 \%$ occurred in low and middle-income regions. It accounted for $31.8 \%$ of all deaths, approximately twice which triggered by cancer (17.1\%) (4). Iran as developing country has affected main demographic variations in recent years. In future decades there will be an increasing and aging population. In fact, because of these epidemiological and demographic shifts, patterns of morbidity and mortality have altered in Iran (5), supporting the necessity for recognition of new biomarkers as risk factors (6). Also, CVD is the major public health burden in Iran, accounting for $50 \%$ of overall mortality and $79 \%$ of deaths due to prolonged diseases (7). It is forecasted that death from CVDs will increase to more than 23.6 million in 2030 (8).

It has been found that rs599839 polymorphism is associated with low levels of cholesterol and reduced coronary heart disease (CHD) (9). Latest genome-wide association studies (GWAS) have acknowledged CELSR2-PSRC1 SORT1 variants on chromosome $1 \mathrm{p} 13.3$ related with $\mathrm{CAD}$ and plasma lipoproteins according to populations of eastern Asia, southern Asia, Middle-Eastern Asia, Africa Americans and European (10).

To the best of our knowledge there is no similar study to assess the relationship between this SNP and CVDs in Iranian population. In the current study, we aimed to investigate the association between rs599839 polymorphism of Proline and Serine Rich Coiled-Coil 1 gene and the clinical CVD outcome in a population enlisted from Mashhad-Stroke and Heart-AtheroscleroticDisorders (MASHAD) cohort from northeast of Iran.

\section{Materials and Methods Study population}

This case- control study consisted of a total of 291 individuals with CVD as well as 218 healthy control subjects who were participants of cohort study in MASHAD. The healthy controls were chosen randomly from individuals of the same sex and age without clinical symptoms of CVD, such as stroke and peripheral arterial disease.

A 10-year cohort research, MASHAD study explores the effect of a wide range of environmental, genetic, psychosocial, and nutritional risk factors on the incidence of cardiovascular disease in an urban population in northeastern Iran. It studied a cohort of 9704 people in the age range of 35 to 65 years and regular follow-ups (11). The eligible patients were determined based on medical interviews and a cardiologist's examination. In the follow-up examinations, individuals with CVD were detected based on their symptoms and multiple diagnostic modalities, such as CT angiography, angiography and ETT were carried out by two interventional cardiologists and an electrophysiologist. The main endpoints included cardiovascular events such as stable/unstable, myocardial infarction, angina and coronary revascularization. Other evaluations included demographic data, anthropometric components and diverse CVD risk factors including fasting blood sugar, blood lipid profile, pressure measurements, and history of hypertension and diabetes. Also, in first population, CAD cases were selected from among patients undergoing coronary angiography at the Ghaem hospital, Mashhad who displayed symptoms of cardiac diseases (ECG changes, chest pain, unstable angina and angina of effort) (12).

The demographic and anthropometric data of individuals in the intervention and control groups are listed in Table 1. The local Ethics and Human Rights Committee confirmed the study design (IR.MUMS.fm.REC.1394.296). Informed consent was obtained from participant. All guidelines of the Helsinki Declaration were observed in this study. Additionally, an informed consent was acquired from all participants prior to the study. 
Table 1. Patient and control group information in cohort.

\begin{tabular}{|c|c|c|c|}
\hline Variables & CVD & Control & p-value \\
\hline \multicolumn{4}{|c|}{ Anthropometrics } \\
\hline \multicolumn{4}{|l|}{ Sex } \\
\hline Women (\%) & $142(48.8)$ & $175(80.3)$ & $\mathrm{p}<0.001$ \\
\hline Age(year) & $60.29 \pm 9.41$ & $55.70 \pm 7.54$ & $\mathrm{p}<0.001$ \\
\hline Smoking & $60(20.6)$ & $45(20.6)$ & 0.95 \\
\hline Height (meter) & $1.60 \pm 0.09$ & $1.59 \pm 0.08$ & $\mathrm{p}<0.001$ \\
\hline Weight(kg) & $71.27 \pm 12.96$ & $64.89 \pm 12.71$ & $\mathrm{p}<0.001$ \\
\hline BMI & $27.61 \pm 4.64$ & $25.40 \pm 3.99$ & 0.196 \\
\hline Waistcir (cm) & $94.53 \pm 12.69$ & $90.35 \pm 10.81$ & $\mathrm{p}<0.001$ \\
\hline \multicolumn{4}{|l|}{ Lipid profile } \\
\hline TC (mg/dl) & $183.33 \pm 47.17$ & $178.16 \pm 30.96$ & $\mathrm{p}<0.001$ \\
\hline TG (mg/dl) & $155.15 \pm 87.30$ & $94.06 \pm 46.46$ & $\mathrm{p}<0.001$ \\
\hline HDL (mg/dl) & $39.74 \pm 12.29$ & $46.06 \pm 10.26$ & 0.324 \\
\hline LDL (mg/dl) & $19.77 \pm 45.56$ & $110.24 \pm 28.44$ & $\mathrm{p}<0.001$ \\
\hline \multicolumn{4}{|l|}{ Vitamins } \\
\hline vit.D (mg/dl) & $2.018 \pm 2.94$ & $1.25 \pm 1.08$ & 0.438 \\
\hline vit.E (mg/dl) & $19.47 \pm 11.744$ & $22.87 \pm 10.62$ & $\mathrm{P}<0.001$ \\
\hline \multicolumn{4}{|l|}{ Blood pressure } \\
\hline SBP (mmHg) & $122.80 \pm 19.73$ & $113.11 \pm 13.40$ & 0.103 \\
\hline DBP (mmHg) & $76.86 \pm 10.56$ & $73.75 \pm 9.39$ & 0.058 \\
\hline Hypertension & $107(36.8)$ & $14(6.4)$ & $\mathrm{p}<0.001$ \\
\hline \multicolumn{4}{|l|}{ Blood glucose } \\
\hline Diabetes (\%) & $83(28.7)$ & $4(1.9)$ & $\mathrm{p}<0.001$ \\
\hline FBS (mg/dl) & $118.45 \pm 63.27$ & $80.02 \pm 13.65$ & $\mathrm{p}<0.001$ \\
\hline
\end{tabular}

$*$ Values are presented as mean \pm SD. Abbreviation: BMI body mass index, SBP systolic blood pressure, DBP diastolic blood pressure, FBG fasting blood glucose, TC total cholesterol, LDL-C low-density lipoprotein cholesterol, HDL-C high-density lipoprotein cholesterol, TG triglycerides, vit.D vitamin D, vit.E Vitamin E, Waist cir Waist circumference.

\section{DNA extraction and genotyping}

Peripheral blood samples were collected from all participants in tubes that contained ethylenediamine tetra acetic acid (EDTA). The genomic DNA extraction was then performed for blood samples by Pistaz teb (Tehran Iran) in keeping with the manufacturer's instructions. The quality and concentration of DNA samples were evaluated by a NanoDrop ${ }^{\circledR}-1000$-Detector device (NanoDrop-Technologies, Wilmington, DE, USA) and 1\% agarose gel electrophoresis, respectively. The DNA samples obtained were then maintained at $-20{ }^{\circ} \mathrm{C}$. The TaqMan ${ }^{\circledR}$ probe-based real-time PCR assay was used to conduct genotype analysis of rs599839 polymorphism in Proline and Serine Rich Coiled-Coil 1 gene. Briefly, the real-time PCR reactions were carried out in $12.5 \mu$ volume. To do so, $20 \mathrm{ng}$ of genomic DNA was used in TaqMan ${ }^{\circledR}$ Universal Master Mix with specific probes and primers (Applied Biosystems, Foster City, CA, USA), as explained in a previous study of authors (13). For the assessment of allelic discrimination in the samples, an ABIPRISM7500 real-time PCR instrument was used. It was equipped with the SDS version-2.0 software that specified the allelic content (14).

\section{Statistical analysis}

In this study, the data with normal and abnormal distribution are displayed as mean $\pm \mathrm{SD}$ or median and interquartile range, respectively. The normal distribution of data in subgroups was evaluated by Kolmogorov-Smirnov tests. To compare the baseline characteristics of participants with/without CVD, we used MannWhitney $\mathrm{U}$ test for non-parametric, student's $t$ test for parametric data, and Pearson's $\chi^{2}$ tests for categorical ones. In addition, Pearson's $\chi^{2}$ tests were used to compare biochemical and demographic variables across the polymorphism. For the assessment of the observed genotype frequencies of the variant of rs599839 in Proline and Serine Rich Coiled-Coil 1 gene and the Hardy-Weinberg equilibrium, $\chi^{2}$ tests were utilized. To evaluate the relationship 
between rs599839 polymorphisms and CVD risk, logistic regression model was employed after adjusting possible confounders, such as sex, age, BMI, cholesterol, and hypertension. Moreover, a Cox regression analyses was used to examine the impact of rs599839 polymorphism upon the incidence of CVD event. $\mathrm{P}$ value $<0.05$ was considered significant. All analyses were conducted by IBM SPSS Statistics 25 (SPSS, Chicago, IL, USA).

\section{Results}

\section{Allele and genotype frequencies in individuals with/without CVDs}

This study was designed to examine the relationship between rs599839 polymorphism in PSRC1 gene and the risk of CVD incidence. For this purpose, TaqMan genotyping was utilized in duplicate for each extracted genomic DNA sample. In all genomic DNA samples, genotyping was effectively accomplished without observing any differences in the duplicates of samples. The findings revealed that the rs599839 polymorphism was not in Hardy-Weinberg equilibrium (HWE) $(p=0.02)$.

Genotype frequencies of rs599839 polymorphism are listed in Table 2 . The frequencies of $\mathrm{AA}, \mathrm{GA}$ and $\mathrm{GG}$ genotypes were $300(58.9 \%), 129(25.3 \%)$ and $80(15.7 \%)$ for rs599839 in the total population, respectively.

Table 2. Patient and control group information.

\begin{tabular}{|c|c|c|c|}
\hline Variables & $\mathbf{C V D}^{\#}$ & Control* & p-value \\
\hline \multicolumn{4}{|l|}{ Anthropometrics } \\
\hline Sex, Women (\%) & $52(50.5)$ & $173(80.1)$ & $\mathrm{p}<0.001$ \\
\hline Height (meter) & $1.61 \pm 0.09$ & $1.59 \pm 0.08$ & 0.19 \\
\hline Weight (kg) & $70.79 \pm 13.62$ & $64.91 \pm 12.77$ & $\mathrm{p}<0.001$ \\
\hline BMI & $27.26 \pm 4.64$ & $25.40 \pm 4.01$ & $\mathrm{p}<0.001$ \\
\hline Waistcir (cm) & $92.65 \pm 12.89$ & $90.31 \pm 10.85$ & $\mathrm{p}<0.001$ \\
\hline Smoking (\%) & $23(22.3)$ & $45(20.8)$ & 0.76 \\
\hline \multicolumn{4}{|l|}{ Lipid profile } \\
\hline $\mathrm{TC}(\mathrm{mg} / \mathrm{dl})$ & $172.70 \pm 45.18$ & $177.76 \pm 30.79$ & 0.324 \\
\hline TG (mg/dl) & $142.24 \pm 78.67$ & $94.38 \pm 46.52$ & $\mathrm{p}<0.001$ \\
\hline HDL (mg/dl) & $39.21 \pm 13.38$ & $46.02 \pm 10.30$ & $\mathrm{p}<0.001$ \\
\hline LDL (mg/dl) & $101.16 \pm 46.33$ & $109.88 \pm 28.32$ & 0.438 \\
\hline \multicolumn{4}{|l|}{ Vitamins } \\
\hline vit.D (mg/dl) & $2.35 \pm 3.43$ & $1.25 \pm 1.08$ & 0.10 \\
\hline vit.E (mg/dl) & $19.28 \pm 11.07$ & $22.87 \pm 10.62$ & 0.058 \\
\hline \multicolumn{4}{|l|}{ Glucose } \\
\hline FBS (mg/dl) & $117.78 \pm 60.25$ & $80.03 \pm 13.70$ & $\mathrm{p}<0.001$ \\
\hline Diabetes $(\%)$ & $(3635)$ & $4(1.9)$ & $\mathrm{p}<0.001$ \\
\hline \multicolumn{4}{|l|}{ Blood pressure } \\
\hline $\mathrm{SBP}(\mathrm{mmHg})$ & $118.13 \pm 17.11$ & $113.05 \pm 13.41$ & $\mathrm{p}<0.001$ \\
\hline DBP (mmHg) & $73.76 \pm 9.01$ & $73.68 \pm 9.40$ & $\mathrm{p}<0.001$ \\
\hline Hypertension & $40(38.8)$ & $14(6.5)$ & $\mathrm{p}<0.001$ \\
\hline
\end{tabular}

*Values are presented as mean \pm SD. Abbreviation: BMI body mass index, SBP systolic blood pressure, DBP diastolic blood pressure, FBG fasting blood glucose, TC total cholesterol, LDL-C low-density lipoprotein cholesterol, HDL-C high-density lipoprotein cholesterol, TG triglycerides, vit.D vitamin D, vit.E Vitamin E, Waist cir Waist circumference.

*: healthy at both baseline/follow-up.

\#: healthy in baseline, but CVD in follow-up. 
The association of rs599839 polymorphism genotypes with the clinical traits of CVD patients

In this study, the link between genotype distribution of rs599839 polymorphism and the clinical traits of CVD patients was investigated either in cohort population or in total population. In Tables 3 and 4, baseline clinical characteristics of participants based on presence/absence of CVD across genotypes are shown in the recessive genetic model. As indicated by the data, the waist circumference was significantly higher than in cohort population than in CVD patients with GG genotype $(103.23 \pm 9.31 \mathrm{~cm})$, in comparison to the patients with AA or GA genotypes (94.69 \pm 11 . 64) $\quad(\mathrm{p}<0.001)$. Weight was significantly higher in the CVD patients with GG genotype $(75.74 \pm 10.65)$ than in patients with AA or GA genotypes $(69.85 \pm 11.68)(p<0.001)$. Also, a significant spike was observed in BMI of CVD patients with GG genotype (30.27 \pm 4.54$)$ in comparison to patients with AA or GA genotypes $\quad(27.02 \pm 4.20) \quad(p<0.001)$. This underscores the fact that people with GG genotype, are at a greater risk of CVD incidence. Additionally, there were no significant difference in blood glucose, lipid profile, systolic blood pressure (SBP), vitamins and diastolic blood pressure (DBP) across the groups. Hypertension was documented in a larger portion of the CVD patients with the GG genotype, as opposed to CVD patients without this genotype $(54.1 \%$ vs. $30.3 \%, \mathrm{p}=0.01)$ (Table 4$)$.

Table 3. Allele and genotype frequencies of rs599839 polymorphisms.

\begin{tabular}{|c|c|c|c|c|c|c|c|}
\hline Gene & SNP & $\begin{array}{l}\text { Major.minor } \\
\text { allele }\end{array}$ & $\begin{array}{c}\text { Major allele } \\
\text { homozygote } \\
(\%)\end{array}$ & $\begin{array}{c}\text { Heterozygot } \\
\text { e }(\%)\end{array}$ & $\begin{array}{c}\text { Minor allele } \\
\text { homozygote } \\
(\%)\end{array}$ & MAF & $\begin{array}{c}\text { HWE } \\
\text { p value }\end{array}$ \\
\hline & rs599839 & $\mathrm{A} / \mathrm{G}$ & $300(58.9 \%)$ & $129(25.3 \%)$ & $80(15.7 \%)$ & 0.29 & 0.44 \\
\hline \multirow{4}{*}{$\begin{array}{l}\text { Total } \\
\text { population }\end{array}$} & & Control* $^{*}(\mathrm{n}=218)$ & $\mathrm{CVD}^{\#}(\mathrm{n}=291)$ & $\begin{array}{l}\text { Total }(\mathrm{n}= \\
509)\end{array}$ & Genetic model & $\mathrm{p}$ value & \\
\hline & $\mathrm{AA}$ & $133(61.0 \%)$ & $167(57.4 \%)$ & $300(58.9 \%)$ & Additive & $<0.001$ & \\
\hline & GA & $72(33.0 \%)$ & $57(19.6 \%)$ & $129(25.3 \%)$ & Recessive & $<0.001$ & \\
\hline & GG & $13(6.0 \%)$ & $67(23.0 \%)$ & $80(15.7 \%)$ & Dominant & 0.41 & \\
\hline \multirow{5}{*}{$\begin{array}{l}\text { Cohort } \\
\text { population }\end{array}$} & & & $178(55.7 \%)$ & $91(28.8 \%)$ & $50(15.6 \%)$ & 0.23 & 0.46 \\
\hline & $\begin{array}{l}\text { Control } \\
(\mathrm{n}=216)\end{array}$ & $\operatorname{CVD}(\mathrm{n}=103)$ & Total $(n=319)$ & $\begin{array}{l}\text { Genetic } \\
\text { model }\end{array}$ & $\mathrm{p}$ value & & \\
\hline & AA & 131(60.6) & $47(45)$ & $178(55.7 \%)$ & Additive & 0.00 & \\
\hline & GA & $72(33.3)$ & $19(18.4)$ & $91(28.8 \%)$ & Recessive & $<0.001$ & \\
\hline & GG & $13(6.0)$ & $37(35.9)$ & $50(15.6 \%)$ & Dominant & 0.01 & \\
\hline
\end{tabular}

Abbreviation: SNP, Single nucleotide polymorphism; MAF, Minor Allele Frequency; HWE, Hardy Wienberg Equilibrium; CVD, Cardiovascular Disease.

*: healthy at both baseline/follow-ups.

\#: healthy in baseline, but CVD in follow-up. 
Table 4. Genotype distribution of rs599838 polymorphism with respect to population features of CVD patients under Recessive genetic model.

\begin{tabular}{|c|c|c|c|c|c|c|}
\hline \multirow{2}{*}{ Variants } & \multicolumn{3}{|c|}{ Without CVD } & \multicolumn{3}{|c|}{ CVD } \\
\hline & GG & $\mathbf{A G}+\mathbf{A A}$ & p value & GG & $\mathbf{A G}+\mathbf{A A}$ & p value \\
\hline \multicolumn{7}{|l|}{ Anthropometrics } \\
\hline Age (year) & $55.07 \pm 8.20$ & $55.74 \pm 7.52$ & 0.66 & $62.67 \pm 9.63$ & $59.56 \pm 9.24$ & 0.01 \\
\hline Sex, Women (\%) & $165(80)$ & $10(76.9)$ & 0.72 & $109(48.7)$ & $33(49.3)$ & 1.00 \\
\hline Height(meter) & $1.59 \pm 0.08$ & $1.59 \pm 0.08$ & 0.96 & $1.59 \pm 0.09$ & $1.611 \pm 0.09$ & 0.23 \\
\hline Weight(kg) & $\begin{array}{l}64.66 \pm 17.4 \\
2\end{array}$ & $64.91 \pm 12.41$ & 0.67 & $73.68 \pm 13.15$ & $70.55 \pm 12.85$ & 0.08 \\
\hline BMI & $25.12 \pm 4.36$ & $25.42 \pm 3.98$ & 0.73 & $29.00 \pm 4.71$ & $27.19 \pm 4.55$ & 0.00 \\
\hline Waistcir (cm) & $\begin{array}{l}89.92 \pm 13.3 \\
8 \\
\end{array}$ & $90.38 \pm 10.67$ & 0.79 & $98.93 \pm 12.46$ & $93.16 \pm 12.47$ & 0.00 \\
\hline Smoking (\%) & $42(20.5)$ & $3(23.1)$ & 0.73 & $40(17.9)$ & $20(29.9)$ & 0.03 \\
\hline \multicolumn{7}{|l|}{ Lipid profile } \\
\hline $\mathrm{TC}(\mathrm{mg} / \mathrm{dl})$ & $\begin{array}{l}173.38 \pm 26 . \\
33\end{array}$ & $178.46 \pm 31.26$ & 0.56 & $193.44 \pm 52.96$ & $180.27 \pm 44.95$ & 0.02 \\
\hline $\mathrm{TG}(\mathrm{mg} / \mathrm{dl})$ & $\begin{array}{l}90.07 \pm 20.2 \\
0\end{array}$ & $94.31 \pm 47.66$ & 0.70 & $162.35 \pm 88.23$ & $152.96 \pm 87.10$ & 0.37 \\
\hline HDL (mg/dl) & $43.14 \pm 7.79$ & $46.24 \pm 10.39$ & 0.28 & $40.01 \pm 11.55$ & $39.66 \pm 12.54$ & 0.22 \\
\hline $\mathrm{LDL}(\mathrm{mg} / \mathrm{dl})$ & $\begin{array}{l}102.51 \pm 31 \\
48\end{array}$ & $110.73 \pm 28.25$ & 0.30 & $118.41 \pm 44.67$ & $107.15 \pm 45.60$ & 0.03 \\
\hline \multicolumn{7}{|l|}{ Blood glucose } \\
\hline FBS (mg/dl) & $\begin{array}{l}76.92 \pm 11.9 \\
4\end{array}$ & $80.22 \pm 13.75$ & 0.37 & $118.32 \pm 62.81$ & $118.48 \pm 63.55$ & 0.99 \\
\hline Diabetes $(\%)$ & $4(0.2)$ & 0 & 0.60 & $60(27)$ & $23(34)$ & 0.24 \\
\hline \multicolumn{7}{|l|}{ Vitamins } \\
\hline vit.D (mg/dl) & $2.06 \pm 2.10$ & $1.20 \pm 0.97$ & 0.21 & $1.44 \pm 1.63$ & $2.17 \pm 3.19$ & 0.32 \\
\hline vit.E (mg/dl) & $29.92 \pm 9.46$ & $22.49 \pm 10.66$ & 0.25 & $18.07 \pm 11.05$ & $19.87 \pm 11.94$ & 0.31 \\
\hline \multicolumn{7}{|l|}{ Blood pressure } \\
\hline $\mathrm{SBP}(\mathrm{mmHg})$ & $\begin{array}{l}111.25 \pm 15 \text {. } \\
65\end{array}$ & $113.23 \pm 13.28$ & 0.37 & $126.89 \pm 22.00$ & $121.59 \pm 18.89$ & 0.11 \\
\hline DBP (mmHg) & $\begin{array}{l}72.48 \pm 10.1 \\
0\end{array}$ & $73.83 \pm 9.37$ & 0.32 & $79.39 \pm 10.12$ & $76.11 \pm 10.59$ & 0.02 \\
\hline Hypertension & $1(7.7)$ & $13(6.3)$ & 0.58 & $28(41.8)$ & $79(35.3)$ & 0.38 \\
\hline
\end{tabular}

Values are presented as mean \pm SD. Abbreviation: BMI body mass index, SBP systolic blood pressure, DBP diastolic blood pressure, FBG fasting blood glucose, TC total cholesterol, LDL-C low-density lipoprotein cholesterol, HDL-C high-density lipoprotein cholesterol, TG triglycerides, vit. D vitamin D, vit. E Vitamin E, Waist cir Waist circumference.

\section{Association of rs599839 with the risk of CVD occurrence}

The statistical analysis based on Pearson's $\chi^{2}$ test showed that in the total population, CVD participants and healthy group were not significantly different in the distribution of minor $\mathrm{G}$ allele ( $\mathrm{p}<044$ in dominant model) (Table 2).
According to the logistic regression analysis, individuals with GA/GG genotypes were at a higher risk of CVDs $(\mathrm{OR}=4.7$; 95\% CI, 2.5-8.7; $\mathrm{p}<0.001$ ) in comparison to those with AA genotype; however, the result was not significant for GG genotype data (Table 5). 
Additionally, the relationship between the alleles of the rs599839 polymorphism and the risk for CVD was examined in patients scheduled for coronary angiography with obstructive coronary artery disease using various genetic models (Table 5). The coronary angiography's indications included MI, stable or unstable angina, and relapse of symptoms following revascularization. The result of multivariate logistic regression analyses adjusted for age, sex and BMI showed a higher risk of CVD incidence in the cohort population $(\mathrm{OR}=1.83$ in the unadjusted dominant model ( $\mathrm{p}=0.01)$ vs. 1.77 in the adjusted dominant model $(\mathrm{p}=0.03))$ (Table 5).

Table 5. genotype distribution of rs599839 polymorphism with respect to population features of CVD patients under Recessive genetic model in cohort study.

\begin{tabular}{|c|c|c|c|c|c|c|}
\hline \multirow{2}{*}{ Variants } & \multicolumn{2}{|l|}{ Without CVD* } & \multirow{2}{*}{ p-value } & \multicolumn{2}{|l|}{ CVD $^{\#}$} & \multirow{2}{*}{ p-value } \\
\hline & $\mathrm{AA}+\mathrm{GG}$ & GG & & $\mathrm{AA}+\mathrm{AG}$ & GG & \\
\hline \multicolumn{7}{|l|}{ Anthropometrics } \\
\hline Age (year) & $55.67 \pm 7.50$ & $55.07 \pm 8.20$ & 0.68 & $64.68 \pm 6.92$ & $65.40 \pm 7.00$ & 0.66 \\
\hline Sex, Women (\%) & $163(80)$ & $10(76)$ & 0.72 & $31(47)$ & $21(56)$ & 0.41 \\
\hline Height (meter) & $1.59 \pm 0.08$ & $1.59 \pm 0.084$ & 0.94 & $1.60 \pm 0.09$ & $1.58 \pm 0.09$ & 0.16 \\
\hline Weight (kg) & $64.92 \pm 12.47$ & $64.66 \pm 17.42$ & 0.66 & $69.85 \pm 11.68$ & $75.74 \pm 10.65$ & 0.00 \\
\hline BMI & $25.42 \pm 4.00$ & $25.12 \pm 4.36$ & 0.73 & $27.02 \pm 4.20$ & $30.27 \pm 4.54$ & 0.00 \\
\hline Waistcir $(\mathrm{cm})$ & $90.33 \pm 10.71$ & $89.92 \pm 13.38$ & 0.80 & $94.69 \pm 11.64$ & $103.23 \pm 9.31$ & 0.00 \\
\hline \multicolumn{7}{|l|}{ Lipid profile } \\
\hline $\mathrm{TC}(\mathrm{mg} / \mathrm{dl})$ & $178.04 \pm 31.09$ & $173.38 \pm 26.33$ & 0.59 & $199.07 \pm 43.18$ & $211.02 \pm 45.72$ & 0.06 \\
\hline $\mathrm{TG}(\mathrm{mg} / \mathrm{dl})$ & $94.66 \pm 47.73$ & $90.07 \pm 20.20$ & 0.73 & $176.45 \pm 100.70$ & $177.21 \pm 93.88$ & 0.86 \\
\hline HDL (mg/dl) & $46.21 \pm 10.43$ & $43.14 \pm 7.79$ & 0.29 & $40.60 \pm 9.81$ & $41.45 \pm 10.32$ & 0.32 \\
\hline LDL (mg/dl) & $110.35 \pm 28.12$ & $102.51 \pm 31.48$ & 0.32 & $122.90 \pm 38.18$ & $131.99 \pm 41.28$ & 0.19 \\
\hline \multicolumn{7}{|l|}{ Blood glucose } \\
\hline FBS (mg/dl) & $80.23 \pm 13.81$ & $76.92 \pm 11.94$ & 0.37 & $120.89 \pm 75.18$ & $115.37 \pm 54.90$ & 0.42 \\
\hline \multicolumn{7}{|l|}{ Vitamins } \\
\hline vit.D (mg/dl) & $1.20 \pm 0.97$ & $2.06 \pm 2.10$ & 0.20 & $1.33 \pm 0.77$ & $1.13 \pm 0.90$ & 0.13 \\
\hline vit.E (mg/dl) & $22.49 \pm 10.66$ & $29.92 \pm 9.46$ & 0.25 & $20.55 \pm 14.21$ & $19.57 \pm 13.95$ & 0.89 \\
\hline \multicolumn{7}{|l|}{ Blood pressure } \\
\hline SBP (mmHg) & $113.16 \pm 13.29$ & $111.25 \pm 15.65$ & 0.38 & $128.43 \pm 19.90$ & $136.37 \pm 22.88$ & 0.17 \\
\hline DBP (mmHg) & $73.76 \pm 9.38$ & $72.48 \pm 10.10$ & 0.34 & $81.56 \pm 11.33$ & $84.45 \pm 9.49$ & 0.19 \\
\hline Hypertension (\%) & $13(6.4)$ & $1(7.7)$ & 0.02 & $20(30.3)$ & $20(54.1)$ & 0.01 \\
\hline
\end{tabular}

Values are presented as mean \pm SD. Abbreviation: BMI body mass index, SBP systolic blood pressure, DBP diastolic blood pressure, FBG fasting blood glucose, TC total cholesterol, LDL-C low-density lipoprotein cholesterol, HDL-C high-density lipoprotein cholesterol, TG triglycerides, vit.D vitamin D, vit.E Vitamin E, Waist cir Waist circumference.*: healthy at both baseline/follow-ups. \#: healthy at baseline, but CVD in follow-up.

Table 6. Multivariable logistic regression analysis of rs599839 polymorphism and CVD under different genetic models.

\begin{tabular}{|c|c|c|c|c|}
\hline & & Genetic models & & \\
\hline Risk allele & & $\begin{array}{l}\text { Additive model OR } \\
(95 \% \mathrm{CI})\end{array}$ & $\begin{array}{l}\text { Recessive model OR } \\
(95 \% \mathrm{CI})\end{array}$ & $\begin{array}{l}\text { Dominant model OR } \\
(95 \% \mathrm{CI})\end{array}$ \\
\hline \multirow{2}{*}{ Total population } & $\begin{array}{l}\text { Unadjusted } \\
\text { model }\end{array}$ & $\begin{array}{l}0.4(0.3-0.7) \\
p=0.001\end{array}$ & $\begin{array}{l}4.7(2.5-8.7) \\
p<0.001\end{array}$ & $\begin{array}{l}1.1(0.8-1.6) \\
p=0.41\end{array}$ \\
\hline & $\begin{array}{l}\text { Adjusted } \\
* \text { model }\end{array}$ & $\begin{array}{l}0.5(0.2-0.8) \\
p=0.01\end{array}$ & $\begin{array}{l}4.2(2.1-8.7) \\
p<0.001\end{array}$ & $\begin{array}{l}1.1(0.7-1.8) \\
p=0.45\end{array}$ \\
\hline \multirow{2}{*}{ Cohort population } & $\begin{array}{l}\text { Unadjusted } \\
\text { model }\end{array}$ & $\begin{array}{l}0.45(0.25-0.80) \\
p=0.00\end{array}$ & $\begin{array}{l}8.75(4.39-17.45) \\
p<0.001\end{array}$ & $\begin{array}{l}1.83(1.14-2.95) \\
\mathrm{p}=0.01\end{array}$ \\
\hline & $\begin{array}{l}\text { Adjusted } \\
* \text { model }\end{array}$ & $\begin{array}{l}0.50(0.27-0.95) \\
p=0.03\end{array}$ & $\begin{array}{ll}1.0 & (0.99-1.00) \\
2.0 & \mathrm{p}=0.24\end{array}$ & $\begin{array}{l}1.77(1.03-3.03) \\
p=0.03\end{array}$ \\
\hline
\end{tabular}

*Adjusted for age, sex, and BMI. 


\section{Discussion}

Our finding showed that CAD patients with GA/GG genotypes for PSRC1gene had a high risk of developing CVD in a representative Iranian population-based cohort. In line with our observations, several GWAS studies have been conducted to determine the genetic basis of genes that put people at high risk for cardiovascular disease. Among several loci in human genome studies identified SNPs at 1p13.3, which have been shown to be linked to CAD and plasma LDL. This locus consist of the genes SORT1, PSRC1, and CELSR2 (15).The Proline-Serine Rich Coiled Coil (PSRC1) gene is accounted for microtubule destabilization (16). The PSRC1 and CELSR2 locus on chromosome 1p13.3 and SNP rs599839 indicated a strong relationship with total cholesterol (17). In particular they showed that the presence of intergenic rs599839 $A>G$ variant was related with reduced the risk of CAD (17). Also, Meroni et al. investigated that the rs599839 $A>G$ variant is associated with protection against dyslipidemia and CVD in NAFLD patients (18). In Musunuru et al. and Zhou et al. study, the more common A allele in $1 \mathrm{p} 13$ loci has been related to augmented risk of ischemic stroke, heart failure, and elevated plasma cholesterol, afterwards modulating lipoprotein metabolism $(19,20)$. Ellis et al. have reported that in patients with cardiovascular disease or people not carrying one or more rs599839 $\mathrm{G}$ allele of polymorphisms at 1p13.3, there was a lower prevalence of dyslipidemia or lower levels of LDL-C and total cholesterol as well as a lower chance of MI compared to AA participants (21). It has been found that the minor G allele of rs599839 and rs646776, and the minor $\mathrm{T}$ allele of rs 12740374 are protective factors against atherosclerosis and cardiovascular disease risk (22). The study of Zhou et al. shows that the minor $G$ allele of rs599839 and rs464218 SNPs is associated with high HDL-C concentrations in CAD and IS patients (10). In agreement with this data, our patients had a high level of TG and low level of HDL, compared to the control group. Arvind et al. showed the minor G allele in the CELSR2-
PSRC1-SORT1 gene cluster has been related to a protection against cardiovascular complications and to a reduction of cholesterol level in CAD patients (23). Rizk et al. suggested that there is a significant association between two polymorphisms of locus 1p13.3 (rs646776 and rs599839) with LDL-C and other lipid profiles. Furthermore, individuals with the Gallele of variant rs599839 had a significant protection against the atherosclerosis (24). Previous studies have demonstrated that rs599839 of PSRC1 is significantly associated with serum LDL-cholesterol levels, wherein the minor $G$ allele is associated with decreased serum LDL-cholesterol (31-35). In Teker et al. study the SORT1 gene encoding Sortilin-1 rs599839 polymorphism does not associate directly to the occurrence of CHD. Though, presence of minor $\mathrm{G}$ allele may lead to lower total-cholesterol and LDL-C levels and higher HDL-cholesterol levels. Therefore, in this way, the presence of the minor $\mathrm{G}$ allele can improve the lipid profile and protect it against CHD disease (25). Munoz-Torrero et al. also, investigated that the frequency of the protective G-allele of the rs599839 polymorphism was reduced in heterozygous familial hypercholesterolemia $(\mathrm{HeFH})$ patients with CHD paralleled with those $\mathrm{HeFH}$ patients without CHD. Though, this conclusion in heterozygous familial hypercholesterolemia patient may be disguised by very high levels of cholesterol in these patients (9).

On the contrary, The GWAS of cardiovascular traits in the Framingham Heart Study, Roslin et al. reported the relationship between rs599839 of the 1p13 and LDL (26). In Sandhu et al. study they found that rs599839 was associated with LDL levels by using GAWS data from 11,685 European individuals (27). The results of Abe et al. study indicated that rs4845625 of IL6R, rs46522 of UBE2Z and rs964184 of ZPR1 were predisposition loci for hypertriglyceridemia, and that rs2075650 of TOMM40 and rs599839 of PSRC1 were such loci that caused hyper-LDL-cholesterolemia in Japanese subjects (28). Han et al. have 
discovered a relationship between the sortilin gene polymorphisms rs599839 and rs464218 and vulnerability to CHD (29). Furthermore, Kleber et al. investigations also confirmed that the genetic variant rs599839 is highly linked with CHD risk and that the genetic variants of chromosome $1 \mathrm{p} 13$ raise the risk of $\mathrm{CHD}$ by increasing total cholesterol and LDL-cholesterol levels and decreasing HDL-cholesterol levels. They also found that rs599839 polymorphism $\mathrm{A} / \mathrm{G}$ in the area of the sortilin 1 gene has been described to be linked with low density lipoprotein cholesterol (LDL-C) and coronary artery disease (CAD) (30). According to our findings, based on the waist circumference, weight, BMI and hypertension individuals with GG genotype are at a higher risk of CVD incidence. After analyzing results of our study indicates that individuals with GA/GG genotypes were at a higher risk of CVDs $(\mathrm{OR}=$ $4.7 ; 95 \% \mathrm{CI}, 2.5-8.7$; $\mathrm{p}<0.001$ ) in comparison to those with AA genotype; however, the result was not significant for GG genotype data.

As far as we know, there is no study on the relationship between rs599839 polymorphism in PSRC1 gene and the risk of CVD occurrence. In the present study, the frequencies of AA, GA and GG genotypes were respectively, $300(58.9 \%), 129(25.3 \%)$ and $80(15.7 \%)$ for rs599839 in total population.

\section{References}

1. Wright KM, Rand KA, Kermany A, Noto K, Curtis D, Garrigan D, et al. A prospective analysis of genetic variants associated with human lifespan. G3 (Bethesda). 2019;9(9):2863-2878.

2. Wang Y, Wang J-G. Genome-wide association studies of hypertension and several other cardiovascular diseases. Pulse (Basel). 2018;6(3-4):169-186.

3. Khanam J, Hossain D, Hosen B, Uddin M, Kabir A, Bari MA. Association of Glutathione S-Transferase theta 1 and mu 1 Genes Polymorphisms with the Susceptibility of Myocardial Infarction in Bangladesh. Rep Biochem Mol Biol. 2020;9(3):366-372.

4. Saglietto A, Manfredi R, Elia E, D'Ascenzo F, GM DF, Munzel T. Cardiovascular disease
The main limitation of present study is to perform functional analysis to explore the potential role of this variant in PSRC1gene with risk of developing and progression of CVDs. Moreover, we performed the value of marker in 1 province, suggesting that other populations are warranted to validate this data.

In conclusion, the results offered in the present study add novel information to the limited body of literature on the significant relationship between rs599839 of PSRC1 gene and cardiovascular events in a population from northeast Iran. The data from the present study indicate that rs599839 polymorphism may be a susceptible SNP for CVDs, although the underlying molecular mechanisms have not been determined definitively. This result is parallel with similar studies, which have been done in other populations and on another locus. Further studies in larger cohorts, may be required to approve the role of this polymorphism and other genes and genetic variants in the development of CVDs events.

\section{Acknowledgements}

We thank all the patients and their family members who volunteered to participate in this study. This work was supported by the Deputy of Research, Mashhad University of Medical Sciences (Grant number 931753).

burden: Italian and global perspectives. Minerva Cardiol Angiol. 2021;69(3)231-240.

5. Sadeghi M, Haghdoost AA, Bahrampour A, Dehghani M. Modeling the burden of cardiovascular diseases in Iran from 2005 to 2025: the impact of demographic changes. Iran J Public Health. 2017;46(4):506-516.

6. Roodi NE, Osguei NK, Daloee MH, Pasdar A, Ghayour-Mobarhan M, Ferns G, et al. Association of endonuclease $\mathrm{G}$ gene variants with cardiovascular disease risk factors. Rep Biochem Mol Biol. 2019;8(2):147-152.

7. Hedayatnia M, Asadi Z, Zare-Feyzabadi R, Yaghooti-Khorasani M, Ghazizadeh $\mathrm{H}$, Ghaffarian-Zirak R, et al. Dyslipidemia and cardiovascular disease risk among the 
MASHAD study population. Lipids Health Dis. 2020;19(1):42.

8. Nakhaie MR, Koor BE, Salehi SO, Karimpour F. Prediction of cardiovascular disease risk using framingham risk score among office workers, Iran, 2017. Saudi J Kidney Dis Transpl. 2018;29(3):608-614.

9. Sanchez Munoz-Torrero JF, Rivas MD, Zamorano J, Joya-Vázquez PP, de Isla LP, Padro $\mathrm{T}$, et al. Multivariate analysis for coronary heart disease in heterozygote familial hypercholesterolemia patients. Per Med. 2018;15(2):87-92.

10. Zhou Y, Yang Q, Yin R. GW26-e2113 Polymorphisms in the CELSR2-PSRC1SORT1 are associated with serum lipid traits, the risk of coronary artery disease and ischemic stroke. J Am Coll Cardiol. 2015;66(16 Supplement):C104-C105.

11. Ghayour-Mobarhan M, Moohebati M, Esmaily H, Ebrahimi M, Parizadeh SM, Heidari-Bakavoli AR, et al. Mashhad stroke and heart atherosclerotic disorder (MASHAD) study: design, baseline characteristics and 10year cardiovascular risk estimation. Int J Public Health. 2015;60(5):561-72.

12. Sadabadi F, Gholoobi A, Heidari-Bakavol A, Mouhebati M, Javandoost A, Asadi Z, et al. Decreased Threshold of Fasting Serum Glucose for Cardiovascular Events: MASHAD Cohort Study. Rep Biochem Mol Biol. 2020;9(1):64-70. 13. Oladi M, Nohtani M, Avan A, Mirhafez SR, Tajbakhsh A, Ghasemi F, et al. Impact of the C1431T Polymorphism of the Peroxisome Proliferator Activated Receptor-Gamma (PPAR- $\gamma$ ) Gene on Fasted Serum Lipid Levels in Patients with Coronary Artery Disease. Ann Nutr Metab. 2015;66(2-3):149-154.

14. Mirhafez SR, Avan A, Pasdar A, Kazemi E, Ghasemi F, Tajbakhsh A, et al. Association of tumor necrosis factor- $\alpha$ promoter G-308A gene polymorphism with increased triglyceride level of subjects with metabolic syndrome. Gene. 2015;568(1):81-4.

15. Kjolby M, Andersen OM, Breiderhoff T, Fjorback AW, Pedersen KM, Madsen P, et al. Sort1, encoded by the cardiovascular risk locus 1p13. 3, is a regulator of hepatic lipoprotein export. Cell metabolism. 2010;12(3):213-23.
16. Al-Eitan LN, Elsaqa BZ, Almasri AY, Aman HA, Khasawneh RH, Alghamdi MA. Influence of PSRC1, CELSR2, and SORT1 gene polymorphisms on the variability of warfarin dosage and susceptibility to cardiovascular disease. Pharmgenomics Pers Med. 2020;13:619-632.

17. Samani NJ, Braund PS, Erdmann J, Götz A, Tomaszewski M, Linsel-Nitschke P, et al. The novel genetic variant predisposing to coronary artery disease in the region of the PSRC1 and CELSR2 genes on chromosome 1 associates with serum cholesterol. J Mol Med (Berl). 2008;86(11):1233-41.

18. Meroni M, Longo M, Paolini E, Alisi A, Miele L, De Caro ER, et al. The rs599839 A> G Variant Disentangles Cardiovascular Risk and Hepatocellular Carcinoma in NAFLD Patients. Cancers (Basel). 2021;13(8):1783.

19. Musunuru K, Strong A, FrankKamenetsky M, Lee NE, Ahfeldt T, Sachs KV, et al. From noncoding variant to phenotype via SORT1 at the 1p13 cholesterol locus. Nature. 2010;466(7307):714-9.

20. Zhou Y-J, Hong S-C, Yang Q, Yin R-X, Cao X-L, Chen W-X. Association of variants in CELSR2-PSRC1-SORT1 with risk of serum lipid traits, coronary artery disease and ischemic stroke. International journal of clinical and experimental pathology. 2015;8(8):9543.

21. Ellis KL, Frampton CM, Pilbrow AP, Troughton RW, Doughty RN, Whalley GA, et al. Genomic risk variants at $1 \mathrm{p} 13.3,1 \mathrm{q} 41$, and $3 \mathrm{q} 22$. 3 are associated with subsequent cardiovascular outcomes in healthy controls and in established coronary artery disease. Circ Cardiovasc Genet. 2011;4(6):636-46.

22. Qin J, Tian J, Liu G, Zhang Y, Tian L, Zhen $\mathrm{Y}$, et al. Association between 1p13 polymorphisms and peripheral arterial disease in a Chinese population with diabetes. J Diabetes Investig. 2018;9(5):1189-1195.

23. Arvind P, Nair J, Jambunathan S, Kakkar VV, Shanker J. CELSR2-PSRC1-SORT1 gene expression and association with coronary artery disease and plasma lipid levels in an Asian Indian cohort. J Cardiol. 2014;64(5):339-46.

24. Rizk NM, El-Menyar A, Egue H, Souleman Wais I, Mohamed Baluli H, Alali K, 
et al. The association between serum LDL cholesterol and genetic variation in chromosomal locus 1p13. 3 among coronary artery disease patients. Biomed Res Int. 2015;2015:678924.

25. Teker E. The effect of SORT1 rs: 599839 polymorphism on lipid profiles in Turkish population. 11 May 2021. PREPRINT available at Research Square. DOI: 10.21203/rs.3.rs474479/v1.

26. Roslin NM, Hamid JS, Paterson AD, Beyene J. Genome-wide association analysis of cardiovascular-related quantitative traits in the Framingham Heart Study. BMC proc. 20093;3,S117.

27. Sandhu MS, Waterworth DM, Debenham SL, Wheeler E, Papadakis K, Zhao JH, etal. LDL-cholesterol concentrations: a genomewide association study. Lancet. 2008;371(9611):483-491.
28. Abe S, Tokoro F, Matsuoka R, Arai M, Noda $T$, Watanabe $S$, et al. Association of genetic variants with dyslipidemia. Mol Med Rep. 2015;12(4):5429-36.

29. Han W, Wei Z, Zhang H, Geng C, Dang R, Yang M, et al. The association between sortilin and inflammation in patients with coronary heart disease. J Inflamm Res. 2020;13:71-79.

30. Kleber ME, Renner W, Grammer TB, Linsel-Nitschke P, Boehm BO, Winkelmann $\mathrm{BR}$, et al. Association of the single nucleotide polymorphism rs599839 in the vicinity of the sortilin 1 gene with LDL and triglyceride metabolism, coronary heart disease and myocardial infarction: the Ludwigshafen risk and cardiovascular Health study. Atherosclerosis. 2010;209(2):492-7. 